\title{
STUDIES OF UREA EXCRETION
}

\section{Vi. Comparison of the Blood Urea Clearance with Certain Other Measures of Renal Function}

\author{
By DONALD D. VAN SLYKE, J. F. MCINTOSH, EGGERT MOLLLER,
}

R. R. HANNON, AND CHRISTOPHER JOHNSTON

(From the Hospital of the Rockefeller Institute for Medical Research, New York)

(Received for publication August 23, 1929)

The data given are from some sixty cases selected from the nephritic patients observed during the past several years in this hospital. The cases selected represent all types of nephritis, hemorrhagic, arteriosclerotic, and degenerative. These cases were chosen because they were the ones which afforded most complete opportunities for observation. Individual clinical reports are outside the possible scope of the present paper, but will be published shortly, elsewhere (Van Slyke, Stillman, et al., 1930).

Möller, McIntosh, and Van Slyke (Studies of Urea Excretion, II, 1928) have described the technique for determining the volume of blood which excretion by the kidneys clears of urea per minute: this volume they term the "blood urea clearance." In another paper (Studies of Urea Excretion, IV , 1928) they have shown that the blood urea clearance is greatly diminished in patients with advanced nephritis. In the present paper data will be reported, indicating the relative sensitiveness of the blood urea clearance as compared with certain other values which are commonly determined to assist in appraising the condition of nephritic patients.

The other values chosen for comparative study have been the concentrations of urea, creatinine, and hemoglobin in the blood, the excretion rate of phenolsulfonephthalein, and the urea concentration ratio, $\frac{\text { urea concentration in urine }}{\text { urea concen tration in blood }}$ Each of these will be discussed in connection with the results obtained. 


\section{METHODS}

Urea in blood and urine was determined, in observations made before 1927, by the method of Van Slyke and Cullen (1914); since then by the manometric method of Van Slyke (1927).

Hemoglobin was determined by the colorimetric method of Palmer (1918), which was standardized and checked at intervals by oxygen capacity determinations according to Van Slyke and Neill (1924).

Creatinine in blood was determined by the colorimetric method of Folin and $\mathrm{Wu}$ (1919). There appears to be uncertainty concerning what proportion of the color measured is actually due to creatinine, but the value determined is in any case the one which has been used during recent years as an indication of renal retention.

Phenolsulfonephthalein excretion was determined by the method of Rowntree and Geraghty (1910). The dye was injected intravenously, and an equal portion of the same stock solution, or a fraction of an equal portion, was used as the standard for colorimetric comparison in the subsequent urine analysis.

\section{Blood urea content}

MacKay and MacKay (1927) have already studied the relationship between the blood urea concentration and the urea excretion ratio of Addis and Watanabe (1916), which is essentially identical with the maximum blood urea clearance, and have found that a large proportion of nephritic patients with low renal functions indicated by the excretion show nevertheless' blood urea nitrogen contents below the normal maximum of $23 \mathrm{mgm}$. per cent.

Möller, McIntosh and Van Slyke (1928) in a paper presenting results with several nephritic cases in which the renal function was damaged in varying degree, stated the relationship between the blood urea clearance and the blood urea concentration in the following words:

"Of the 5 cases with urea excreting power, as indicated by the blood urea clearances, consistently reduced to from 40 to 12 per cent of the average normal, all except one showed at times blood urea nitrogen below the maximum (23 mgm. per cent) found by MacKay and MacKay (1927) in normal subjects. These results confirm the conclusions of these authors, that more than half the functioning tissue of the kidneys may be destroyed before the blood urea rises above normal limits. 
In such subjects with renal loss the blood urea may, in fact, be éven less than the normal average. . . . . It has been common on our wards to find consistently normal blood urea content in nephritic patients who have lost 40 to 60 per cent of their renal function. Such patients are likely, either by choice or by direction, to take diets low in protein: and if they consume half as much as a given normal subject, other factors being equal, they will show about the same urea content. If, in addition, they drink more water, they may have even less blood urea than many normal subjects."

TABLE 1

Illustrating change in blood urea concentration without change in blood urea clearance or clinical condition*

Hospital No. 6545. Boy of 18. Terminal hemorrhagic nephritis. Protein in diet limited to $\mathbf{4 0}$ grams daily after first observation.

\begin{tabular}{|c|c|c|c|c|c|}
\hline \multirow[b]{2}{*}{ Date } & \multirow{2}{*}{$\begin{array}{c}\text { Blood urea } \\
\text { nitrogen } \\
B\end{array}$} & \multirow[b]{2}{*}{ 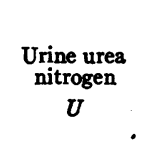 } & \multirow[b]{2}{*}{$\begin{array}{c}\text { Urine volume } \\
V\end{array}$} & \multicolumn{2}{|c|}{ Standard blood urea clearance } \\
\hline & & & & $\begin{array}{c}\begin{array}{c}\text { Cc. blood } \\
\text { per minute }\end{array} \\
\frac{U}{B} \sqrt{V}\end{array}$ & $\begin{array}{l}\text { Per cent of } \\
\text { average } \\
\text { normal clear- } \\
\text { ance }\end{array}$ \\
\hline 1928 & mgm. per cent & mgm. per cent & cc. per minute & $c c$. & per cent \\
\hline October 23 & $\begin{array}{l}141 \\
141\end{array}$ & $\begin{array}{l}381 \\
355\end{array}$ & $\begin{array}{r}1.84 \\
1.84\end{array}$ & $\begin{array}{l}3.6 \\
3.4\end{array}$ & $\begin{array}{l}6.8 \\
6.3\end{array}$ \\
\hline October 31 & $\begin{array}{l}128 \\
128\end{array}$ & $\begin{array}{l}466 \\
416\end{array}$ & $\begin{array}{l}1.02 \\
1.17\end{array}$ & $\begin{array}{l}3.7 \\
3.4\end{array}$ & $\begin{array}{l}6.9 \\
6.5\end{array}$ \\
\hline November 8 & $\begin{array}{l}93 \\
93\end{array}$ & $\begin{array}{l}216 \\
217\end{array}$ & $\begin{array}{l}1.54 \\
1.74\end{array}$ & $\begin{array}{l}2.9 \\
2.9\end{array}$ & $\begin{array}{l}5.4 \\
5.7\end{array}$ \\
\hline November 21 & $\begin{array}{l}57 \\
57\end{array}$ & $\begin{array}{l}208 \\
179\end{array}$ & $\begin{array}{l}1.06 \\
1.47\end{array}$ & $\begin{array}{l}3.8 \\
3.8\end{array}$ & $\begin{array}{l}7.0 \\
7.0\end{array}$ \\
\hline
\end{tabular}

* This case was continually on the verge of uremia. He continued with clearances varying from 4.5 to 7 per cent of normal for 6 months, and then died in uremia. During this period the blood urea nitrogen varied up and down over most of the above range, with practically constant low clearance.

The data in figure 1 serve as illustration and proof of the above statement. All the points within the rectangle indicate observations in nephritic cases in which the blood urea clearance had sunk below the minimal normal value, and in which the blood urea contents were nevertheless within the normal range. It is seen that until the blood urea clearance has fallen below $\mathbf{5 0}$ per cent of average normal, all the blood urea contents are within the rectangle. With clearances 
between 20 and 40 per cent of average normal, more than half the blood urea contents are still within the normal maximum. It is only when renal function, as measured by the clearance, has fallen to less than 20 per cent of normal that a great part of the blood urea concentrations become definitely elevated.

These results illustrate the uncertainty which attends the interpretation of normal blood urea concentration values in nephritic patients if urea excretion is not also taken into consideration.

It is not possible to discuss here the clinical features of the individual cases, but we may say that clinical observation indicated that the patients with low blood urea clearances had diseased kidneys; and that whether or not the blood urea content was above normal, the clearance indicated regularly the decrease in renal function leading to uremia long before the blood urea, considered without regard for the urine urea, indicated the progress of the disease.

After nephritis has progressed sufficiently far to cause a permanent elevation in blood urea nitrogen the latter is likely to undergo variations which are obviously unrelated to any essential change in pathological process in the kidneys, while the blood urea clearance remains com' paratively constant. Table 1 illustrates such a case.

\section{Blood creatinine content}

Figure 2 gives results of a comparison of blood creatinine determinations with blood urea clearances. It is obvious that a rise of blood creatinine above $2 \mathrm{mgm}$. per cent has approximately the same significance as a rise of blood urea nitrogen above $23 \mathrm{mgm}$. per cent, and that the remarks made above concerning the relative insensitiveness of the blood urea concentration as an indicator of developing renal insuffciency can also be applied to the blood creatinine.

Figs. 1 and 2. Relationship of Blood URea Nitrogen Concentration and Blood Creatinine Concentration to Blood Urea Clearance in NePHRITIC PATIENTS

The points enclosed in rectangles represent urea or creatinine values found within normal limits when the renal function, measured by the blood urea clearance, was below the normal minimum.

The numbers indicating percentages of normal clearance, and corresponding to the vertical lines through both charts, are at the bottom of the upper chart. 


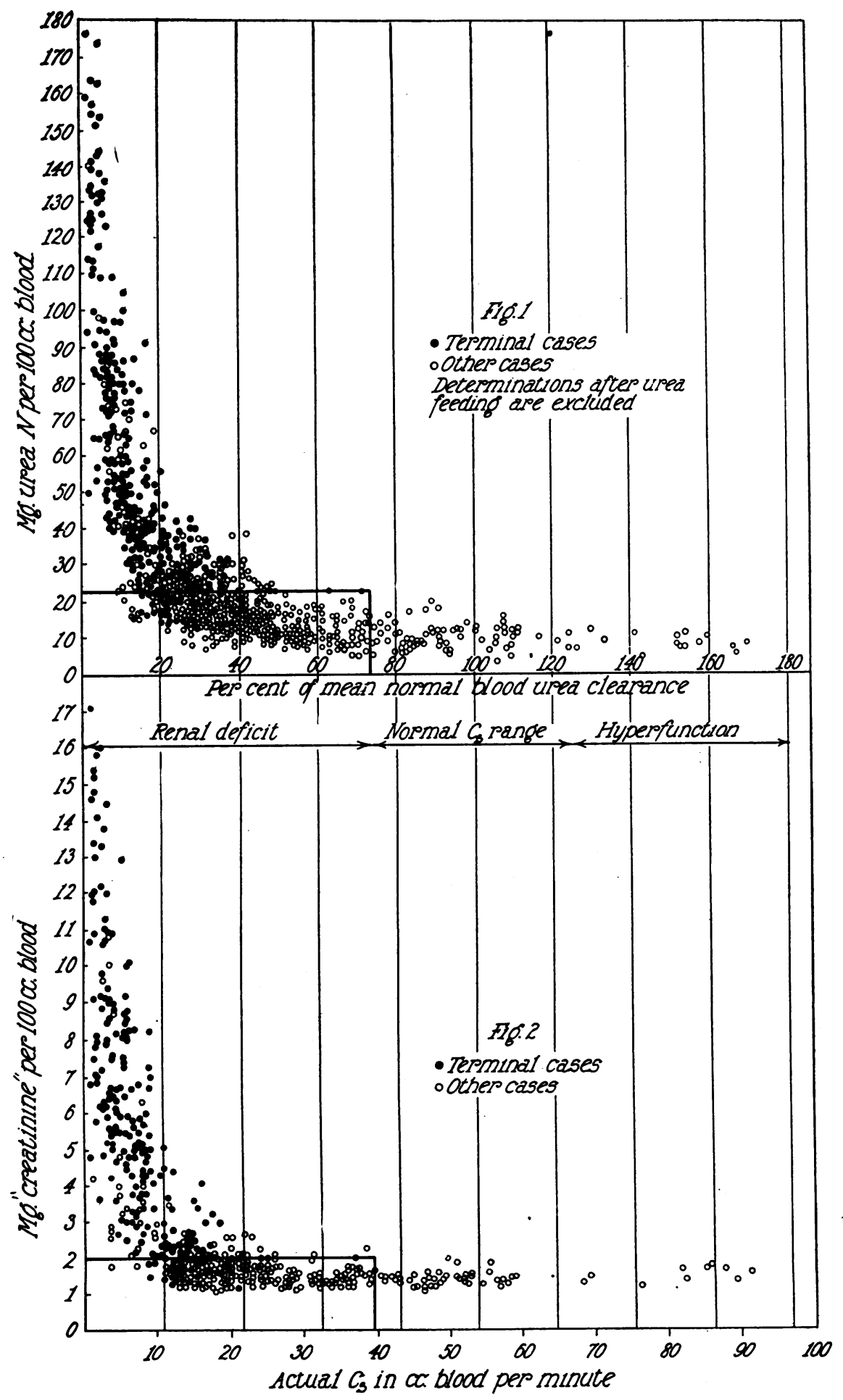


The high creatinine values indicated by hollow circles were observed during temporary depression of renal function in acute nephritis. Like low clearances and high blood urea contents during the acute period, they do not necessarily indicate a bad prognosis, as will be shown in a forthcoming paper (Van Slyke, Stillman, Möller, et al., 1930).

\section{Blood hemoglobin content}

That anemia is a nearly constant accompaniment of advanced renal disease has been long recognized, and Brown and Roth (1922, 1923) have published data showing that the gravity of the prognosis increases with the anemia.

The data in figure 3 indicate a somewhat greater degree of correlation in advanced nephritis between anemia and renal deficit than was noted between blood urea and creatinine contents and such deficit. Of the group of cases with 20 to 40 per cent of average normal blood urea clearance nearly four-fifths have under 90 per cent of Haldane's normal hemoglobin value; their oxygen capacities are less than 16.6 volumes per cent. With one exception all the advanced chronic cases with less than 20 per cent of normal clearance showed hemoglobin contents below this level. (The points indicated by hollow circles above the 90 per cent line are from acute cases.)

While all advanced chronic cases showed hemoglobin below the usual normal limits, the fall in hemoglobin was by no means parallel to the fall in blood urea clearance. Some of the cases with less than 10 per cent of normal blood urea clearance showed over 80 per cent of normal hemoglobin; we have seen such cases develop uremia.

The interpretation of Brown and Roth $(1922,1923)$ that anemia is a sign of bone marrow injury resulting from toxic retention appears to be

Figs. 3 and 4. Relationship of Blood Hemoglobin Content and of the Phenolsulfonephthalein Excretion to Blood Urea Clearance in NePhritic Patients

The points enclosed in rectangles represent hemoglobin or phthalein excretion values found within normal limits when the renal function, measured by the blood urea clearance, was below the normal minimum.

The numbers indicating percentages of normal clearance, and corresponding to the vertical lines through both charts, are at the bottom of the upper chart. 


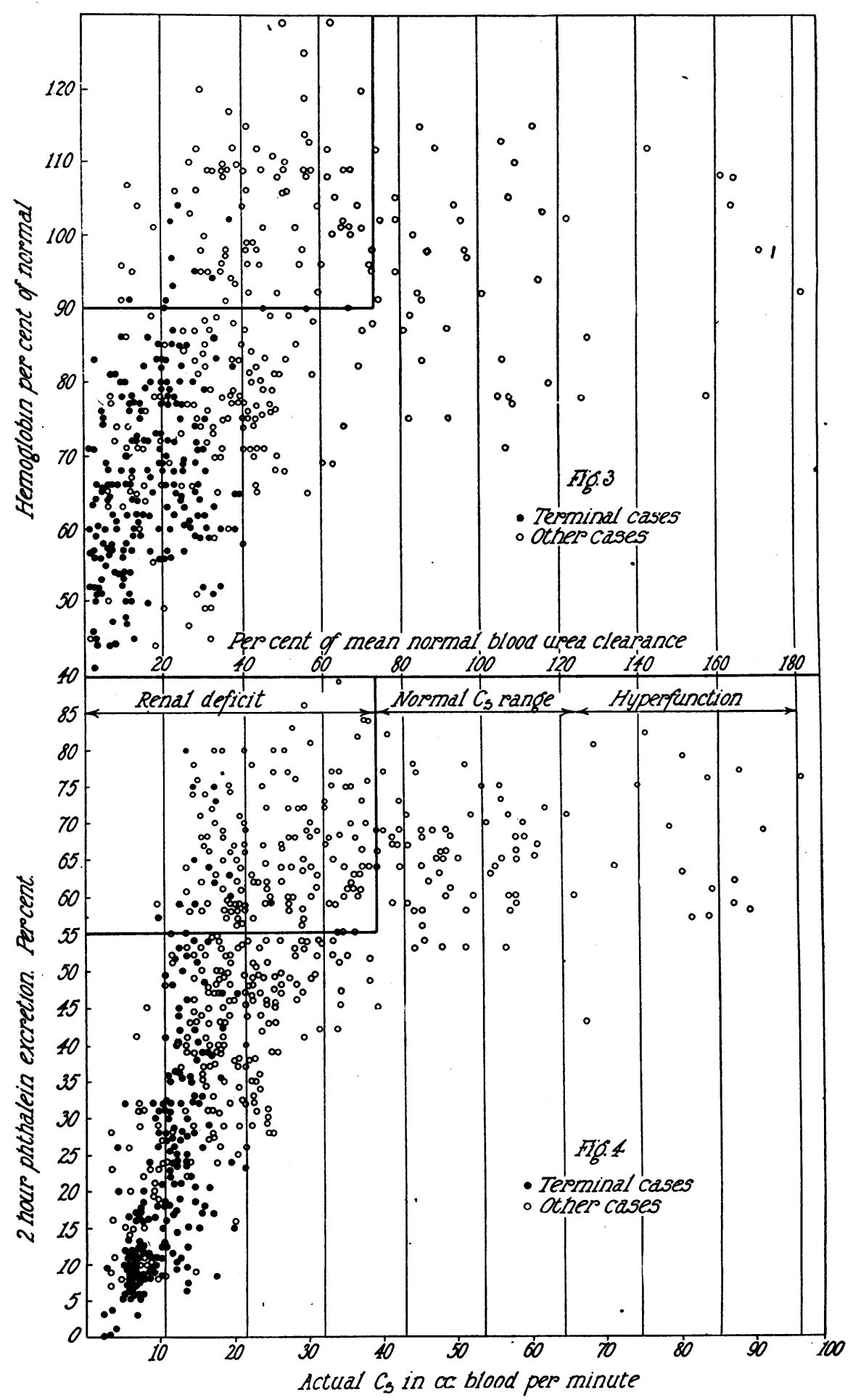


well founded. It is not surprising that in some cases the toxins should affect the hematopoietic organs more than in other cases with the same degree of renal deficit.

As will be shown elsewhere (Van Slyke, Stillman, Möller, et al., 1930) the onset of uremia is connected with the degree of loss of urea excreting power rather than with the degree of anemia.

\section{Phenolsulfonephthalein excretion}

- The phenolsulfonephthalein excretion measurement introduced by Rowntree and Geraghty (1910) has been one of the most useful of renal tests. During the past ten years it has been uniformly determined simultaneously with the blood urea clearance in the studies here reported. The points in figure 4 represent. the percentages excreted in 2 hours.

The rectangle in figure 4 encloses points which represent normal phthalein values obtained in cases with low blood urea clearances, and is drawn with the low line at the level indicating 55 per cent of injected dye excreted in 2 hours.

Roughly the degree of numerical correlation between phthalein output and clearance may be expressed as follows:

With the clearance between 40 and 60 per cent of normal average, about half the phthalein outputs are above and half below 55 per cent of the dye injected.

With the clearance between 20 and 40 per cent of normal, approximately three-fourths of the phthalein excretions are below 55 per cent of the dye injected. However, some patients with only 25 to 30 per cent of renal function measured by the clearance show phthalein excretions high even for normal individuals.

With the clearance below 20 per cent of normal all the phthalein excretions are low, and in most cases to a degree corresponding to the clearance.

Figures 5, 6, 7, and 8, each representing data collected during a number of months on a single patient with changing renal function, indicate in some detail the manner in which the phthalein excretion lags in time behind the blood urea clearance as an indicator of renal deficit. In general, observation has shown that when the renal function is falling the blood urea clearance registers the fact some weeks or months 
before the phthalein excretion does. The behavior is what one would expect if the phthalein and urea were put out by different parts of the secreting elements, and if damage to the kidneys uniformly tended to strike the urea-excreting portions first, ultimately affecting the phthalein excreting portions as the pathological process advanced. (We do not advance this as even an hypothetical explanation of what actually occurs in the kidney, but merely as a picture which perhaps helps one to remember the relative behavior of the two tests.)

In figure 5 are shown data from a case first examined one month after the onset of acute hemorrhagic nephritis, which showed blood urea clearance of only 25 to 30 per cent normal, while the phthalein output was still entirely within the usual normal range, and continued to be so for 3 weeks longer. Then, with an exacerbation of a stomatitis, the blood urea clearance fell to nearly zero, and the phthalein suddenly fell to a similar level.

During subsequent recovery of this case an interesting phenomenon is noted, which we have seen also in other cases improving from acute hemorrhagic nephritis. The phthalein excretion of the improving patient shows a definite rise sooner, and thereafter rises more rapidly towards normal, than does the blood urea clearance. In figure 5 the shaded area representing functional deficit narrows more rapidly with the successive months in the case of the phthalein output than in the case of the blood urea clearance. It is as though the damage not only affected the phthalein excreting portions later, but also, during recovery, left them sooner, than the urea excreting parts.

Figure 6 represents an acute hemorrhagic case in which the blood urea clearance fell to 40 to 50 per cent of normal, remained there for 2 months, and during the subsequent 2 months rose again to normal, while throughout the entire time the phthalein output showed not the slightest indication that anything was happening in the kidney.

In figure 7 somewhat the same phenomenon is shown, except that the acute hemorrhagic nephritis here developed into chronic, ending in total renal failure and uremia. In this case from the 6th to the 20th month of observation the blood urea clearance varied between 30 and 50 per cent of normal. During this entire period the phthalein excretion in only one instance was less than 50 per cent of the injected dye, and several times was nearly 70 per cent. After the 21 st month of 
observation the blood urea clearance suddenly fell to between 5 and 10 per cent of normal, and uremia set in. Only then did the phthalein excretion show an undoubted functional deficit.

In figure 8 are shown observations on a case that had had an acute hemorrhagic attack following scarlet fever. If there had been any functional deficit at the time it apparently had nearly or quite disappeared, for when the patient came under observation 2 years later the blood urea clearance was just at the lower border of the range observed in normal subjects. At successive admissions during the next 2 years a steady fall in both blood urea clearance and phthalein excretion was observed, until finally death in uremia occurred. It will be noted that at the second admission the clearance had fallen to 50 per

Figs. 5, 6, 7 and 8. Blood Hemoglobin Contents, Phenolsulfonephthalein Excretions, and Blood Urea Clearances in 4 Nephritic Patients

For each value the mean normal is drawn as a base line; the shaded area between the base line and the points representing observations indicates the degree of deviation above or below the average normal.

The scale running from 0 to 100 for each of these 3 values represents percentages of average normal. In addition to this scale in each case there is to the left another giving results in absolute units: the hemoglobin in volumes per cent of oxygen capacity, the phthalein excretion in per cent of the intravenously injected dye excreted in two hours; the standard blood urea clearance in cubic centimeters of blood cleared of urea per minute.

Near the bottom of each figure, as further indications of the patient's condition, are given approximate representations of the degrees of edema, proteinuria, and hematuria observed. The black areas have the following significances:

\begin{tabular}{|c|c|c|c|}
\hline $\begin{array}{l}\text { Height of black } \\
\text { area in fifths } \\
\text { of total space }\end{array}$ & Edema & $\begin{array}{c}\text { Proteinuria; } \\
\text { Protein per } 24 \text { hours }\end{array}$ & Hematuria \\
\hline 1 & Trace & Under 1 gram & Slight microscopic \\
\hline 2 & Moderate pitting & 1 to 4 grams & Marked microscopic \\
\hline 3 & Marked pitting & 4 to 10 grams & Slight macroscopic \\
\hline 4 & General edema with ascites & Over 10 grams & Marked macroscopic \\
\hline
\end{tabular}

At the bottom of each chart the number at the left nearest "Months" indicates the number of months the disease was noted before the patient entered the hospital. The other numbers in the bottom row indicate months after first admission.

Spaces left unshaded in the upper part of the charts indicate periods during which no observations were made, usually because the patient was out of the hospital. 

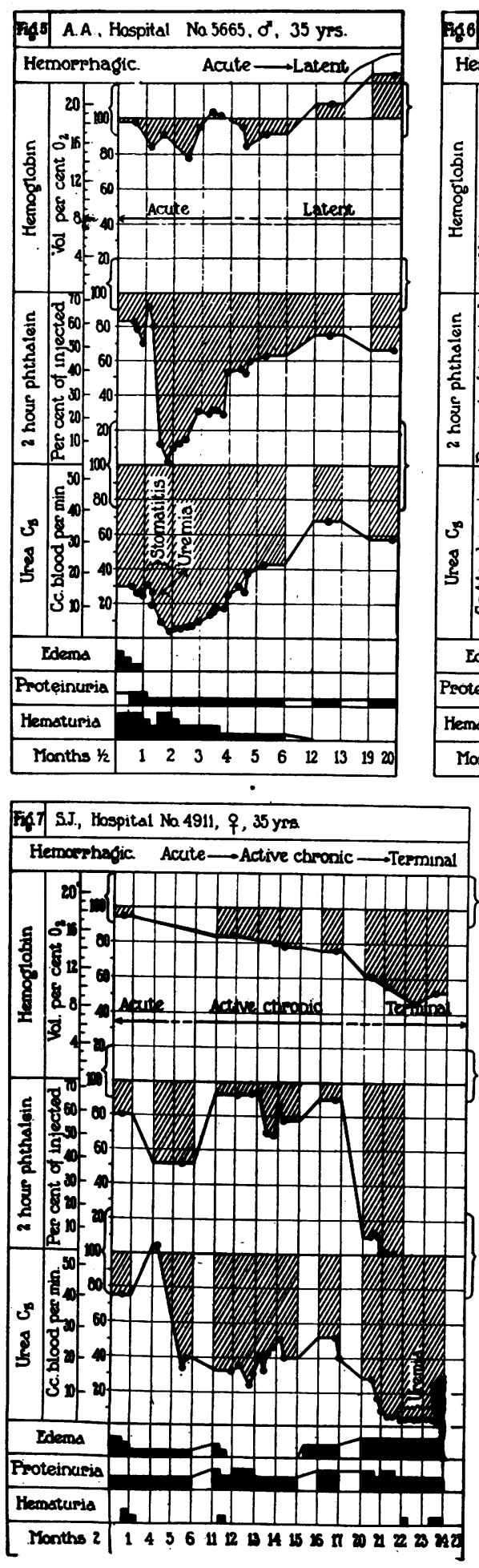
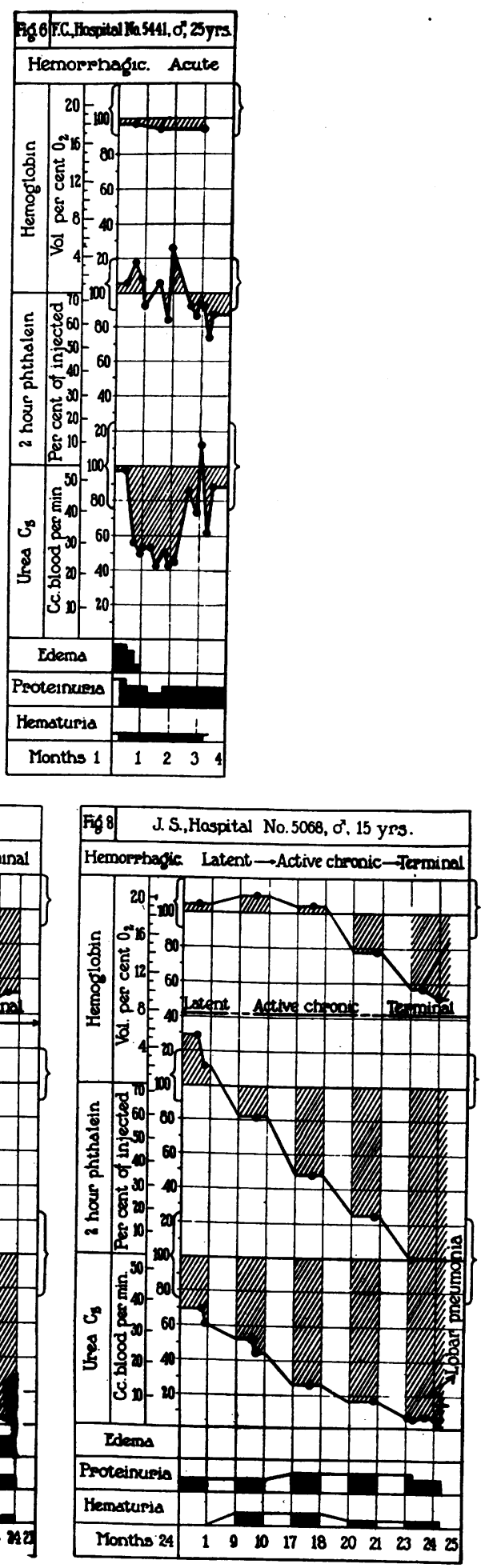
cent of average normal, while the phthalein excretion was still normal, 60 per cent of the dye being put out in 2 hours. On the third admission, 7 months later, clearance was reduced to 28 per cent of normal, and by this time the phthalein showed a definite effect, the excretion being down to 28 per cent of the injected phthalein in 2 hours. The phthalein had been apparently several months behind the clearance, however, in showing the developing renal deficit.

Divergence between phthalein excretion and blood urea clearance due to bladder retention

In two cases, briefly observed in consultation, the phthalein excretion in two hours was only about 5 per cent; while the standard clearance was unusually variable, but in the neighborhood of half the normal value, indicating much better function than the phthalein. In both cases the bladder was found to hold continually a large volume of urine, because of prostatic obstruction. In consequence most of the phthalein entering the bladder in 2 hours was diluted and retained in the urine already there, only a fraction being voided in the portion of the urine passed after 2 hours. The urea of the voided urine was not diluted as was the phthalein, and the blood urea clearance values, although variable, averaged more nearly in accordance with the functional ability of the kidneys.

In both these cases the diagnosis of the prostatic condition was made by examination suggested as the result of the peculiar divergence between the two functional tests.

The ratio $\frac{\text { urine urea concentration }}{\text { blood urea concentration }}$, observed with low or moderate urine volumes

In the standard blood urea clearance formula, $\frac{U}{B} \sqrt{ } \bar{V}$, the volume as a factor plays a somewhat subordinate rôle as shown by the fact that it appears only as a square root. ( $U$ signifies urea concentration in urine, $B$ the urea concentration in blood, and $V$ the urine volume in cc. per minute.) By a number of previous authors (Gréhant, 1904; Harrison, 1922; Rabinowitch, 1928; Starr and Ballard, 1927) the 
simple $U / B$ ratio without correction for volume has been used as a measure of renal function. Harrison, however, emphasized the fact that most consistent results were obtained when the urine volumes were below $150 \mathrm{cc}$. per hour.

In fact when the urine volume output is below 2 cc. per minute the $U / B$ ratio does not as a rule differ greatly from the standard clearance.

In figure 9 are shown results obtained with ten nephritic patients on each of whom a number of standard blood urea clearances have been determined during a period in which the renal function showed no obvious tendency to change in either direction. Only observations are

TABLE 2

Ranges covered by $\frac{U}{B}$ and $\frac{U \sqrt{V}}{B}$ values in ten nephritic patients with varying degrees of renal insufficiency

\begin{tabular}{c|c|c}
\hline Case number & Range of $\frac{U}{B}$ values & Range of $\frac{U \sqrt{V}}{B}$ values \\
\hline 1 & $2.3-4.1$ & $2.0-3.8$ \\
2 & $2.1-10.0$ & $2.0-9.3$ \\
3 & $2.1-6.9$ & $1.8-4.9$ \\
4 & $3.0-9.4$ & $6.4-8.7$ \\
5 & $10.0-18.5$ & $11.5-17.5$ \\
6 & $10.0-24$ & $9.0-20$ \\
7 & $17-41$ & $19-37$ \\
8 & $15-57$ & $29-58$ \\
9 & $15-59$ & $21-52$ \\
10 & $41-84$ & $51-86$ \\
\hline
\end{tabular}

recorded in which the urine volume per minute was less than 2 cc. The states of renal function in the series of cases cover the entire range that one is likely to observe, from no. 1 on the verge of uremic death to no. 10 with a clearance at the upper limit of the normal range. The values are plotted on a logarithmic scale, in order to make a given percentage variation show the same width of scattering of points in subjects with low clearances as in those with high ones.

It is obvious from figure 9 that the $U / B$ values cover ranges differing but little from the $\frac{U \sqrt{V}}{B}$ values. That the variation of results in each patient is diminishd by including the volume as a factor is, however, 


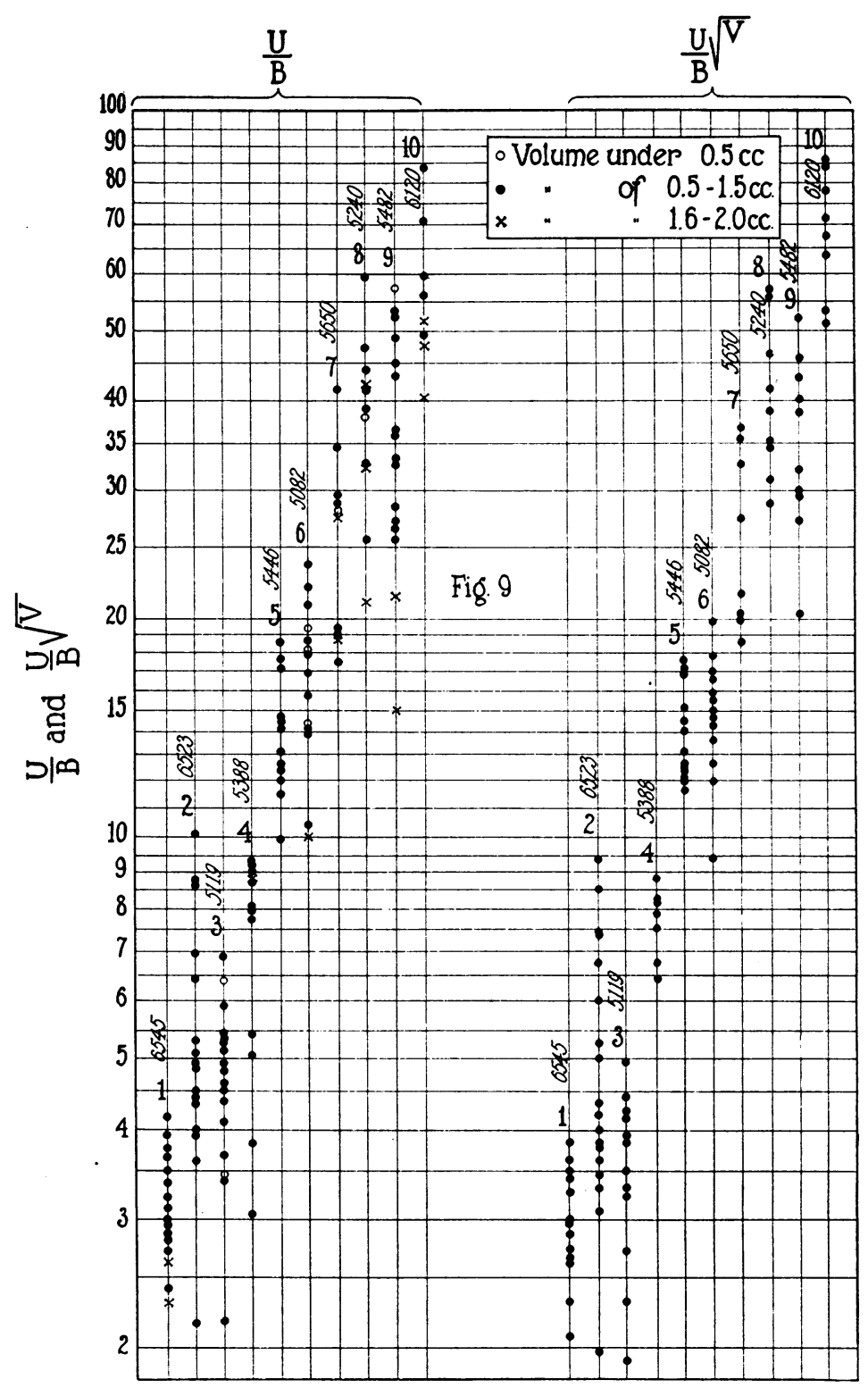

Fig. 9. Comparison in Ten Nephritic Patients of the Range of the Values of the Urea Concentration Ratio, $\frac{U}{B}=\frac{\text { Urea Concentration in. Urine }}{\text { Urea Concentration in BLOOD }}$ with the Range of Values of the Standard Blood Urea Clearance, $\frac{U \sqrt{V}}{B}$

Observation in which the urine volume exceeded $2 \mathrm{cc}$. per minute are excluded. 
shown by table 2 . It is consequently preferable to calculate the standard clearance rather than the $U / B$ concentration ratio whenever the urine volume can be satisfactorily measured. In all cases measurement of the urine volume is desirable, for without measurement one can not be entirely sure that the volume does not exceed $2 \mathrm{cc}$. per minute and climb into the high levels where only maximum blood urea clearances are of significance. Determination of the $U / B$ concentration ratio, without volume measurement, is an alternative which one can use when necessary, and which usually gives results nearly the same as the standard clearance if precautions are taken to avoid diuresis.

Of all the tests examined, determination of the $U / B$ ratio is the only one that approximates in sensitiveness the measurement of the blood urea clearance.

Sometimes determination of this $U / B$ ratio is a useful alternative to a clearance determination. In an occasional patient, with retention, or incontinence, or sometimes for no obvious reason, it is difficult to obtain a complete voiding of the urine secreted by the kidneys in a given time. Such a condition may be deduced from bizarre fluctuations in urine volume without corresponding variations in the urea concentration. With precautions to keep the urine volume within ordinary limits, as near as possible to $1 \mathrm{cc}$. per minute, one can in such a patient use the $U / B$ ratio in place of the standard clearance. When this procedure is followed, it is of course especially desirable to make repeated observations.

\section{SUMMARY}

In patients with diminishing renal function the blood urea clearance shows evidence of the diminution sooner than does the blood creatinine content, the blood urea content considered without relation to the urea excretion, or the phenolsulfonephthalein excretion. The blood urea clearance usually falls below 50 per cent of its normal value before any of the other 3 values shows any abnormality. Only after the blood urea clearance indicates less than 20 per cent of normal renal function are all values for blood urea and creatinine content, and for phenolsulfonephthalein excretion, found outside the limits. of normal variation. 
In cases with diminishing renal function the phenolsulfonephthalein excretion is likely to register entirely normal values for some weeks or months after the blood urea clearance indicates less than 50 per cent of average normal renal function.

In cases improving from acute nephritis with severe functional deficit, the phenolsulfonephthalein excretion sometimes shows a marked rise several weeks in advance of rise in the blood urea clearance. In such cases the phthalein excretion has an especial interest.

In bladder retention, phthalein excretion is likely to be very low in comparison with the blood urea clearance, or the ratio Urea concentration in urine , because of the fact that only a fraction of the phthalein excreted into the bladder is likely to be voided in 2 hours. For this reason, comparison of phthalein excretion and blood urea clearance can be of assistance in detecting retention.

A considerable degree of correlation was noted between the development of anemia and fall in blood urea clearance. Cases of chronic nephritis with less than 12 volumes per cent of blood oxygen capacity, or 65 per cent of Haldane's normal hemoglobin content, all showed less than 40 per cent of normal renal function measured by the blood urea clearance.

However, as shown by figures $5,6,7$, and 8 , hemoglobin content is likely to fall much later in the disease than the blood urea clearance. Hemoglobin contents over 80 per cent of normal are maintained by some uremic cases with blood urea clearances reduced to less than 10 per cent of normal. A low blood hemoglobin content in nephritis is a grave prognostic sign, but a fairly good hemoglobin content does not indicate in every case a better prognosis.

The simple concentration ratio, $\frac{\text { Urea concentration in urine }}{\text { Urea concentration in blood }}$ observed when the urine volume is less than $2 \mathrm{cc}$. per minute, preferably less than $100 \mathrm{cc}$. per hour, has approximately the same mean normal numerical value, about 50 , as the standard blood urea clearance, and is equally sensitive to diminution in renal function. In a given individual the ratio shows more variation than the clearance because the ratio lacks correction for urine volume changes; but it serves well as a substitute for the clearance when, because of incontinence, retention, 
or other reason, the urine volume output within a definite period can not be measured.

\section{BIBLIOGRAPHY}

Addis, T., and Watanabe, C. K., J. Biol. Chem., 1916-17, xxviii, 251. A Method for the Measurement of the Urea Excreting Function of the Kidneys.

Brown, G. E., and Roth, G. M., Arch. Int. Med., 1922, xxx, 817. The Anemia of Chronic Nephritis: J. Am. Med. Assoc., 1923, Ixxxi, 1948. Prognostic Value of Anemia in Glomerular Nephritis.

Folin, O., and Wu, H., J. Biol. Chem., 1919, xxxviii, 98. A System of Blood Analysis.

Gréhant, N., J. Physiol. et Path. gen., 1904, vi, 1. Mesure de l'activité physiologique des reins par le dosage de l'urée dans le sang et dans l'urine.

Harrison, G. A., Brit. J. Exp. Path., 1922, iii, 28. On Urea Tests of Renal Function.

MacKay, E. M., and MacKay, Lois, L., J. Clin. Invest., 1927, iv, 127. The Relation between the Blood Urea Concentration and the Amount of Functioning Renal Tissue.

MacKay, E. M., and MacKay, Lois, L., J. Clin. Invest., 1927, iv, 295. The Concentration of Urea in the Blood of Normal Individuals.

Möller, E., McIntosh, J. F., and Van Slyke, D. D., J. Clin. Invest., 1928, vi, 427. Studies of Urea Excretion. II. Relationship between Urine Volume and Rate of Urea Excretion by Normal Adults.

Möller, E., McIntosh, J. F., and Van Slyke, D. D., J. Clin. Invest., 1928, vi, 485. Studies of Urea Excretion. IV. Relationship between Urine-Volume and Rate of Urea Excretion by Patients with Bright's Disease.

Palmer, W. W., J. Biol. Chem., 1918, xxxiii, 119. The Colorimetric Determination of Hemoglobin.

- Rabinowitch, I. M., Arch. Int. Med., 1923, xxxii, 927. The Urea Concentration Factor in the Estimation of Renal Efficiency.

Rowntree, L. G., and Geraghty, J. T., J. Pharm. and Exp. Therap., 1910, i, 579. An Experimental and Clinical Study of the Functional Activity of the Kidneys by Means of Phenolsulphonephthalein.

Starr, P., and Ballard, F., J. Clin. Invest., 1927, v, 101. The Blood-Urine Urea Concentration Ratio in Hypertension.

Van Slyke, D. D., J. Biol. Chem., 1927, lxxiii, 695. Determination of Urea by Gasometric Measurement of the Carbon Dioxide Formed by the Action of Urease.

Van Slyke, D. D., and Cullen, G. E., J. Biol. Chem., 1914, xix, 211. A Permanent Preparation of Urease and Its Use in the Determination of Urea.

Van Slyke, D. D., and Neill, J. M., J. Biol. Chem., 1924, lxi, 523. The Determination of Gases in Blood and Other Solutions by Vacuum Extraction and Manometric Measurement. 
Van Slyke, D. D., Stillman Edgar, Möller, Eggert, Ehrich, W., McIntosh, J. F., Leiter, L., MacKay, E. M., Hannon, R. R., Moore, N. S., and Johnston Christopher, Medicine, 1930, (in press). Observations on the Courses of Different Types of Bright's Disease, and on the Resultant Changes in Renal Anatomy. 